\title{
Modeling and Model Comparison for Industrial Production Index of Turkey, Brazil and G7 Countries
}

\author{
Nihan Öksüz Narinç ${ }^{1}$ \\ ${ }^{1}$ Namik Kemal University, Vocational School of Social Sciences, \\ 59100, Tekirdag, Turkey
}

\begin{abstract}
:
In this study, it was aimed to modeling and model comparison for the industrial production index values of Turkey, Brazil and G7 countries among the years 1990-2017. The curve estimation methods (linear, quadratic, qubic, and hyperbolastic) and some non-linear time series models (Weibull, Negative Exponential, Brody, Gompertz, Logistic, Von Bertalanffy, Richards) were used for modeling the longitudinal data of monthly industrial production index values. The most fitted Gompertz model for all three data sets was determined according to the criteria of goodness of fit (coefficient of determination, mean square error, Akaike's information criterion, Bayesian information criterion), using the process between 1990-2008 (up to the 2008 crisis). After the 2008-2009 crisis, Brazil and G7 countries' industrial production index values were well below their expected values. In contrast, Turkey's expected values and the actual values for the industrial production index have been fairly close. Considering these results, it can be said that Turkey was less affected in terms of the effects of the 2008-2009 economic crisis than other countries. Industrial production index values of Turkey at $100^{\text {th }}$ anniversary of the founding of the Republic of Turkey in 2023 and other important date in 2050 were estimated to be 177.62 and 485.63, respectively.
\end{abstract}

Keywords: Industrial production index, Nonlinear regression, Time series, Financial crisis.

\section{Introduction}

The military, economy and politics of all the countries of the world are in relationship because of technology, globalization and inter-country loyalty. These relations reveal groupings or differentiations, by this way solidarity and competition arise between countries. One of the most important factors determining this relation is the economic situation that is the economic power (Kormendi and Miguere, 1985). The financial markets around the world have been linking each other since the end of the $20^{\text {th }}$ century (Schneider, 2015). Within this structure, particularly developing countries have begun to be evaluated within certain groups according to various criteria (Altay and Güçlï, 2005). An example of this situation, it can be demonstrated the relationship to Turkey and Brazil in the early 2000s. Turkey was compared with Latin American countries until the 2000-2001 crisis, in the later years mostly evaluated together with Brazil. Some similarities about economy and politics between Turkey and Brazil led them to be described as "twin brothers" in previous years. The reasons for this metaphor are as follows: the economic crises that the two countries have experienced in succession, and then two countries owed most to the International Monetary Fund as a result of these crises, and after very strong governments have come to power without the support of a coalition partner in both countries (Yalçın and Telatar, 2008).

In particular, the economic indicators of countries are taken into account in the classification made by various organizations. Among these criteria, Gross National Product (GNP), per capita national income, foreign trade activities, export volume and industrialization level of the country are the most widely used indicators (Forbes and Rigobon, 2002). In general, the high level of national income and industrial production, and the high export quantity indicate that the country has developed. Some of the macroeconomic indicators required to measure economic developments are calculated by governments from data obtained with various measures. One of the most important macroeconomic indicators is the industrial production index ( $\mathrm{Wu}$ and $\mathrm{Xia}, 2016)$. In the industrial production index, mining industry, manufacturing industry and electricity, gas and 
water sectors are included. Although the value added of the industrial sector is only one part of the total economy, historically, the industrial production index covers most of the fluctuations in total production.

The industrial production index of Turkey has been firstly calculated at first three months of 1983 based on data of 1981 by Turkish Statistical Institute (TUIK). In Turkey, the release of capital movements since the second half of 1989 and the removal of obstacles in the flow of foreign direct investment have been important steps in terms of industrialization. In order to create a dynamic economic structure led by the private sector and suitable for international competition environment, policies have been introduced to liberalize the foreign exchange regime, to increase liberalization in imports, and to facilitate the export of foreign capital. There were the effects of external factors on the basic approaches to industrialization, and on the formation of related policies. The application for full membership of the European Union in 1987 and the accession to Customs Union in 1995 resulted in policy changes affecting industrialization in a significant way. The important precautions taken in this regard were follows; the resetting custom rates in the trade of industrial goods between European Union and Turkey, and the determination of the common customs tariff, harmonization of subsidies to European Union membership, taking property rights into more active protection, taking precautions that prevent unfair competition, and the prevent competition infringements. After these applications Turkey economy gradually improved. In this study, it was aimed to compare the industrial production index of Turkey, Brazil and G7 countries using the monthly industrial production index values among 1990 to 2017. In order to make a comparison, the most fitted model for all three data sets was determined according to the criteria of goodness of fit, using the process between 1990-2008 (up to the 2008 crisis). Then, using the most suitable model, the harmonization with the process after the 2008 crisis was compared. Finally, 2023, 2037 and 2050 estimates of industrial production index of Turkey, Brazil and G7 countries were obtained and interpreted.

\section{Body Text}

In this study, the monthly industrial production index values of Turkey, Brazil and G7 countries among 1990 to 2017 years were obtained from the OECD (The Organization for Economic Co- operation and Development) (https://data.oecd.org/ industry/industrial-production.htm, last access date: 03.25.2018). This indicator is measured in an index based on 2010 that expresses change in the volume of production output. Seasonal and calendar adjustments of data were performed. The graphical representation of the entire data is presented in Figure 1.

Figure 1 shows that the crisis covering the years 2008-2009 has affected the industrial production index values of Turkey, Brazil and G7 countries. Therefore, the period between 1990 and 2008 was modeled separately for Turkey, Brazil and G7 countries. The curve estimation methods (linear, quadratic, qubic, and hyperbolastic) and some nonlinear time series models (Weibull, Neagetive Exponential, Brody, Gompertz, Logistic, Von Bertalanffy, Richards) were used for modeling the longitudinal data of monthly industrial production index values (Preacher and Hayes, 2004; Tabatabai et al., 2005). Curve estimation models are presented below;

- Linear;

$\mathrm{w}_{\mathrm{t}}=\mathrm{a}+\beta_{0} \mathrm{t}$

- Quadratic; $\mathrm{w}_{\mathrm{t}}=\mathrm{a}+\beta_{0} \mathrm{t}+\beta_{1} \mathrm{t}^{2}$

- Qubic; $\mathrm{w}_{\mathrm{t}}=\mathrm{a}+\beta_{0} \mathrm{t}+\beta_{1} \mathrm{t}^{2}+\beta_{2} \mathrm{t}^{3}$

- Hyperbolastic; $w_{t}=\beta_{0} /\left(1+\beta_{1} \exp \left(-\beta_{0} \beta_{2} t-\beta_{4} \operatorname{arcsinh}(\mathrm{t})\right)\right)$

In equations, $w_{t}$ is any at time point of industrial production index value; $a$ is the model constant; $\beta_{0}$, $\beta_{1}, \beta_{2}$, and $\beta_{4}$ are model parameters that characterize the shape of the curve. The equations of the nonlinear time series (smooth transition autoregressive; STAR) models used in the study are presented below;

- Morgan-Mercer Flodin;

$$
w_{t}=\left(\beta_{0} \beta_{1}+\beta_{2} t^{\beta_{3}}\right) /\left(\beta_{1}+t^{\beta_{3}}\right)
$$

- Negative exponential;

$$
w_{t}=\beta_{0}\left(1-\exp \left(-\beta_{2} t\right)\right)
$$

- Brody;

$$
w_{t}=\beta_{0}\left(1-\beta_{1} \exp \left(-\beta_{2} t\right)\right)
$$

- Gompertz;

$$
w_{t}=\beta_{0} \exp \left(-\beta_{1} \exp \left(-\beta_{2} t\right)\right)
$$

- Logistic;

$$
w_{t}=\beta_{0} /\left(1+\beta_{1} \exp \left(-\beta_{2} t\right)\right)
$$

- Von Bertalanffy;

$$
w_{t}=\beta_{0}{ }^{1-\beta_{3}}-\beta_{1} \exp \left(\left(-\beta_{2} t\right)^{1 / 1-\beta_{3}}\right)
$$


- Richards;

$$
w_{t}=\beta_{0} /\left(1+\beta_{1} \exp \left(-\beta_{2} t\right)\right)^{1 / \beta_{3}}
$$

In all models, wt is any at t time point of industrial production index value, $\beta_{0}$ asymptotic expected value of industrial production index at infinite time, $\beta_{1}$ (scale parameter) is related to initial value of index, $\beta_{2}$ growth rate of the function, $\beta_{3}$ allometric constant of the model. All smooth transition autoregressive models were estimated by the Marquardt algorithm using the NLIN procedure of the SAS program (SAS Institute. 1999). The following goodness of fit criteria were used to determine the fitness of all models (Park and Phillips, 2008);

- The coefficient of determination;

$$
\mathrm{R}^{2}=1-(\mathrm{SSE} / \mathrm{SST})
$$

where, SSE: Sum square of errors, SST: Total sum square.

- Mean square error;

$$
\mathrm{MSE}=\sum_{\mathrm{i}=1}^{\mathrm{n}}\left(\mathrm{Y}_{\mathrm{i}}-\hat{\mathrm{Y}}_{\mathrm{i}}\right)^{2} /(\mathrm{n}-\mathrm{k})
$$

where $\sum_{i=I}^{n}\left(Y_{i}-\hat{Y}_{i}\right)^{2}$ is total sum square, $\mathrm{n}$ is the number of observations, $\mathrm{k}$ is the number of parameters.

- Akaike's information criterion

$$
\mathrm{AIC}=\mathrm{n} \cdot \ln (\mathrm{SSE} / \mathrm{n})+2 \mathrm{k}
$$

where, $\mathrm{N}$ : the number of observations, SSE: Sum square of errors, $\mathrm{k}$ : the number of parameters.
- Schwarz Bayesian information criterion $\mathrm{BIC}=\mathrm{n} \cdot \ln (\mathrm{SSE} / \mathrm{n})+\mathrm{k} \cdot \ln (\mathrm{n})$

where, $\mathrm{N}$ : the number of observations, SSE: Sum square of errors, $\mathrm{k}$ : the number of parameters

\section{Result and Discussion}

The parameter estimations and the goodness of fit criteria ( $\mathrm{R}^{2}$, MSE, AIC, BIC) computed using curve estimation models (Linear, Quadratic, Qubic, Hyperbolastic) and smooth transition autoregressive models (Weibull, Neagetive Exponential, Brody, Gompertz, Logistic, Von Bertalanffy, Richards) were shown in Table 1, Table 2, Table 3 for G7 countries, Brazil and Turkey, respectively.

As seen in Table 1, Table 2 and Table 3, the goodness of fit values of the curve estimation models are worse than the nonlinear regression models. Teräsvirta and Anderson (1992) have compared the industrial production indices among 1961-1986 of Germany, United States, Austria, Belgium, England, Italy, Sweden, Japan and Canada with nonlinear regression models. Researchers have reported that the Logistic and Exponential models were sufficient and descriptive. Thus, researchers have also shown that an economic variable such as an industrial production index can be modeled in nonlinear models. The findings obtained from this study are also compatible with the findings of Teräsvirta and Anderson (1992).

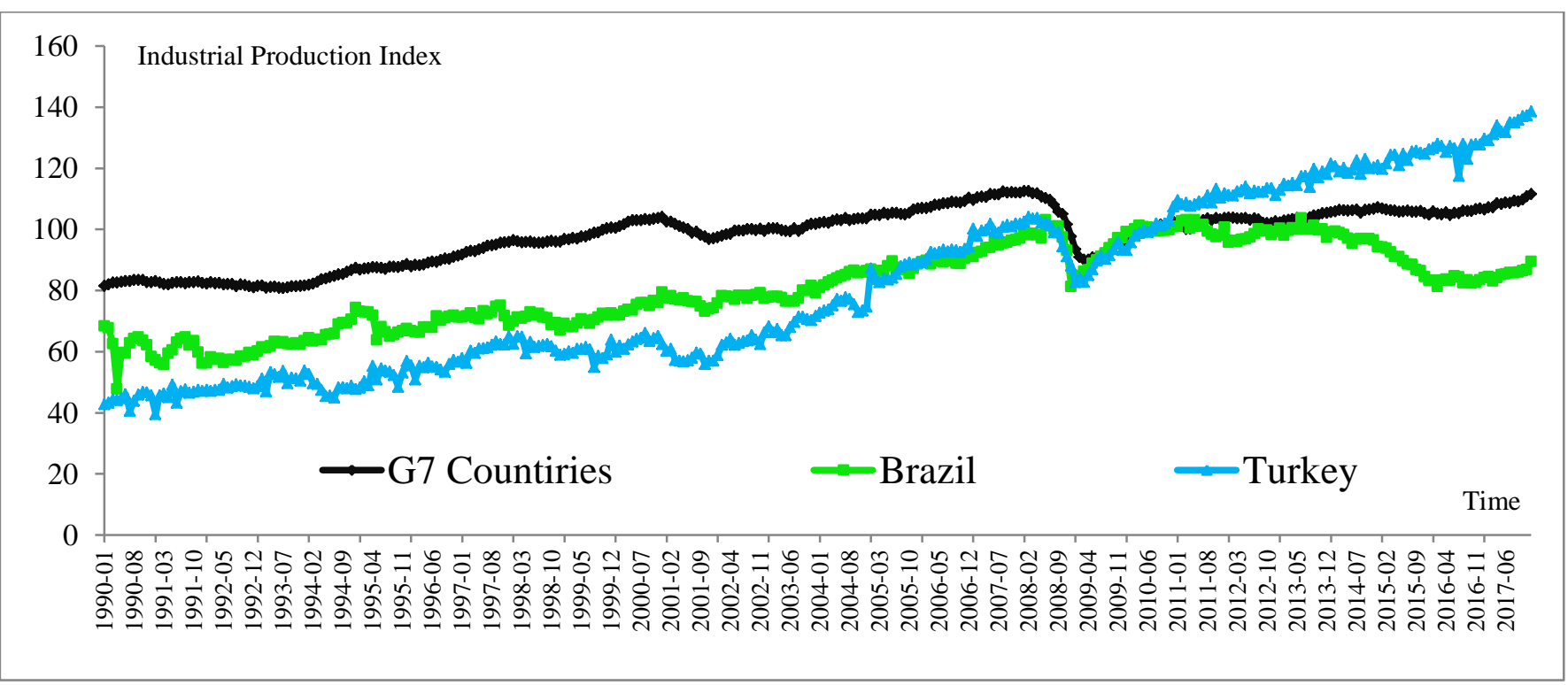

Figure 1. The monthly industrial production index values of Turkey, Brazil and G7countries among 1990 to 2017 (based on 2010) 
The use of non-linear smooth transition autoregressive models in the modeling of macroeconomic data is limited. Karaduman (2008) investigated asymmetric behavior of growth rate, which is proxied by quarterly industrial production index running from 1980 to 2006 in Turkey. In mentioned study, Logistic smooth transition autoregressive modeling procedure was employed to data given some evidence on asymmetric behavior of growth rate in Turkey and justified the usage of Logistic model (Karaduman, 2008).

The highest $R^{2}$ values (99.0160-99.9374) for G7 countries were obtained from Hyperbolastic, Negative Exponential, Gompertz, Logistic, Von Bertalanffy, Richards models. In addition, the lowest MSE (5.15-5.82), AIC (358.08-382.97) and BIC (393.09-409.22) values were found in Weibull, Brody, Gompertz, Logistic and Richards models (Table 1). For Brazil, the highest $\mathrm{R}^{2}$ values (99.7740-99.8243) were obtained from Gompertz, Logistic, Von Bertalanffy, Richards models. Besides the lowest MSE (9.04-10.20), AIC (479.55-504.70) and BIC (514.55-530.96) values were found in Weibull, Gompertz, and Logistic models (Table 2). The highest $\mathrm{R}^{2}$ values (99.3118-99.2599) for Turkey were obtained from Hyperbolastic, Gompertz, Logistic, and Richards models. In addition, the lowest MSE (29.36-31.56), AIC (734.02-749.70) and BIC (760.27-775.95) values among nonlinear regression models were found in Hyperbolastic, Weibull, Gompertz, Logistic and Richards models (Table 3).
Weibull, Gompertz and Logistic models gave the best results when evaluating the goodness of fit criteria for monthly industrial production index data of all three countries. In the period from 2008-2009 crisis to 2017, the estimated values of the Gompertz model were used to make comparison with observations and predictions for G7 countries, Brazil and Turkey's industrial production index values. Thus, the estimated values and actual values obtained in the post-crisis period were compared using actual data before the 2008-2009 crisis. The results obtained are presented in Figure 2. When the predicted and actual values are compared, it is seen that the Brazil and G7 countries' industrial production index values after the crisis were well below their expected values (Figure 2). In contrast, Turkey's expected values and the actual values for the industrial production index have been fairly close. Considering these results, it can be said that Turkey was less affected in terms of the effects of the 2008-2009 economic crisis than other countries.

The predictions of the monthly industrial production index values using Gompertz model for G7 countries, Brazil and Turkey from 2017 to 2050 are also shown in Figure 3. The mean values of industrial production index of Turkey in 2023, and 2050 were estimated as 177.62, and 485.63, respectively. These predictions were $132.88,196.44$, and 235.46 and 135.36, 158.99, and 168.69 for Brazil and G7 countries, respectively.

Table 1. Parameter estimations and goodness of fit criteria for studied models of monthly industrial production index values (1990-2008) of G7countries

\begin{tabular}{lccccccccc}
\hline Model & Constant & $\beta_{0}$ & $\beta_{1}$ & $\beta_{2}$ & $\beta_{3}$ & $\mathrm{R}^{2}$ & MSE & AIC & BIC \\
\hline Linear & 78.892 & 0.15 & & & - & 93.6874 & 5.78 & 379.09 & 387.84 \\
Quadratic & 78.756 & 0.15 & $-1.7 \times 10^{-5}$ & & - & 93.6913 & 5.81 & 380.96 & 398.46 \\
Qubic & 79.984 & 0.08 & 0.0010 & 0.0000 & - & 93.9156 & 5.63 & 375.13 & 401.39 \\
Hyperbolastic & - & 117.2 & $2.3 \times 10^{-5}$ & 0.3888 & - & 99.5953 & 37.37 & 787.07 & 811.32 \\
Weibull & - & 113.50 & -32.8270 & 0.0002 & 1.7410 & 94.4293 & 5.15 & 358.08 & 393.09 \\
Neagetive Exponential & - & 95.05 & - & 1.5994 & - & 99.0160 & 90.42 & 976.95 & 1003.21 \\
Brody & - & 640.70 & 0.8771 & 0.0003 & - & 93.6908 & 5.81 & 382.97 & 409.22 \\
Gompertz & - & 220.20 & 1.0283 & 0.00186 & - & 99.9372 & 5.79 & 382.45 & 408.70 \\
Logistic & - & 172.40 & 1.1886 & 0.00349 & - & 99.9374 & 5.78 & 382.01 & 408.26 \\
Von Bertalanffy & - & 103.5 & 0.0275 & 0.0148 & 0.9372 & 99.8054 & 18.05 & 628.85 & 653.10 \\
Richards & - & 208.7 & 0.1563 & 0.0021 & 0.149 & 99.9372 & 5.82 & 382.38 & 408.63 \\
\hline
\end{tabular}


Table 2. Parameter estimations and goodness of fit criteria for studied models of monthly industrial production index values (1990-2008) of Brazil

\begin{tabular}{lccccccccc}
\hline Model & Constant & $\beta_{0}$ & $\beta_{1}$ & $\beta_{2}$ & $\beta_{3}$ & $\mathrm{R}^{2}$ & MSE & AIC & BIC \\
\hline Linear & 56.381 & 0.16 & & & - & 89.5481 & 11.41 & 525.93 & 534.68 \\
Quadratic & 60.057 & 0.06 & 0.0005 & & - & 91.9783 & 8.80 & 470.77 & 488.27 \\
Qubic & 57.750 & 0.18 & -0.0010 & $4.4 \times 10^{-6}$ & - & 92.6435 & 8.11 & 454.07 & 480.33 \\
Hyperbolastic & - & 544.00 & $2.4 \times 10^{-6}$ & 0.1176 & - & 99.5773 & 23.63 & 688.07 & 712.32 \\
Weibull & - & 1891.00 & -1830.2 & $3.1 \times 10^{-5}$ & 1.6140 & 91.7990 & 9.04 & 479.55 & 514.55 \\
Neagetive Exponential & - & 73.54 & - & 0.7129 & - & 98.0395 & 109.10 & 1017.45 & 1043.70 \\
Brody & - & 2666.80 & 0.9789 & 0.0001 & - & 89.4979 & 11.52 & 530.97 & 557.22 \\
Gompertz & - & 3377.20 & 4.0792 & 0.0006 & - & 99.8174 & 10.20 & 504.70 & 530.96 \\
Logistic & - & 644223 & 11211.3 & 0.0022 & - & 99.8243 & 9.78 & 496.46 & 522.71 \\
Von Bertalanffy & - & 151.30 & 1.1969 & 0.0026 & 0.6963 & 99.7740 & 12.69 & 552.80 & 577.06 \\
Richards & - & 1748.30 & 0.0245 & 0.0007 & 0.00707 & 99.8158 & 10.29 & 506.61 & 532.87 \\
\hline
\end{tabular}

Table 3. Parameter estimations and goodness of fit criteria for studied models of monthly industrial production index values (1990-2008) of Turkey

\begin{tabular}{lccccccccc}
\hline & Constant & $\beta_{0}$ & $\beta_{1}$ & $\beta_{2}$ & $\beta_{3}$ & $\mathrm{R}^{2}$ & MSE & AIC & BIC \\
\hline Linear & 38.034 & 0.23 & & & - & 83.2625 & 42.01 & 807.36 & 816.11 \\
Quadratic & 48.469 & -0.06 & 0.0013 & & - & 91.7802 & 20.73 & 655.76 & 673.26 \\
Qubic & 40.243 & 0.39 & -0.0038 & $1.6 \times 10^{-5}$ & - & 95.4576 & 11.51 & 529.65 & 555.90 \\
Hyperbolastic & - & 9521.2 & $4.1 \times 10^{-7}$ & 0.0152 & - & 99.2711 & 31.25 & 748.44 & 772.69 \\
Weibull & - & 426.50 & -376.8 & $9.3 \times 10^{-9}$ & 3.0876 & 92.8247 & 18.18 & 630.41 & 665.41 \\
Neagetive Exponential & - & 74.88 & - & 0.0243 & - & 95.2599 & 202.20 & 1150.81 & 1177.06 \\
Brody & - & 6774.9 & 0.9944 & $3.4 \times 10^{-5}$ & - & 83.2115 & 42.33 & 812.02 & 838.27 \\
Gompertz & - & 21904.4 & 6.3119 & 0.0007 & - & 99.2636 & 31.56 & 748.61 & 774.86 \\
Logistic & - & 1622140 & 40448.9 & 0.0039 & - & 99.3118 & 29.36 & 734.02 & 760.27 \\
Von Bertalanffy & - & 161.50 & 2.1786 & 0.0033 & 0.6606 & 98.9291 & 46.12 & 831.51 & 855.76 \\
Richards & - & 14342.6 & 0.0049 & 0.0007 & 0.0008 & 99.2599 & 31.72 & 749.70 & 775.95 \\
\hline
\end{tabular}

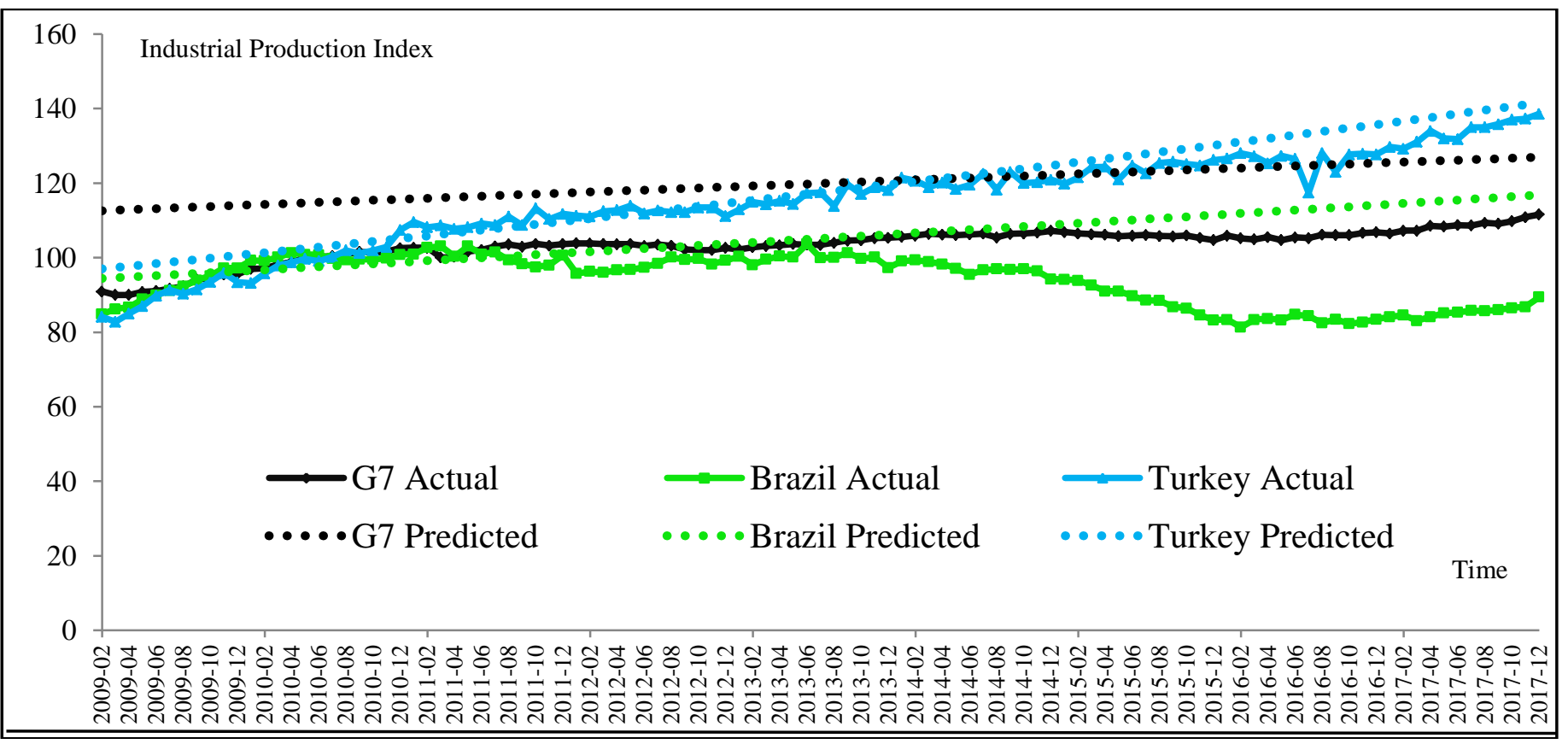


Figure 2. Actual and predicted (via Gompertz) monthly industrial production index values of Turkey, Brazil and G7countries in the period from 2008-2009 crisis to 2017 (based on 2010 data)

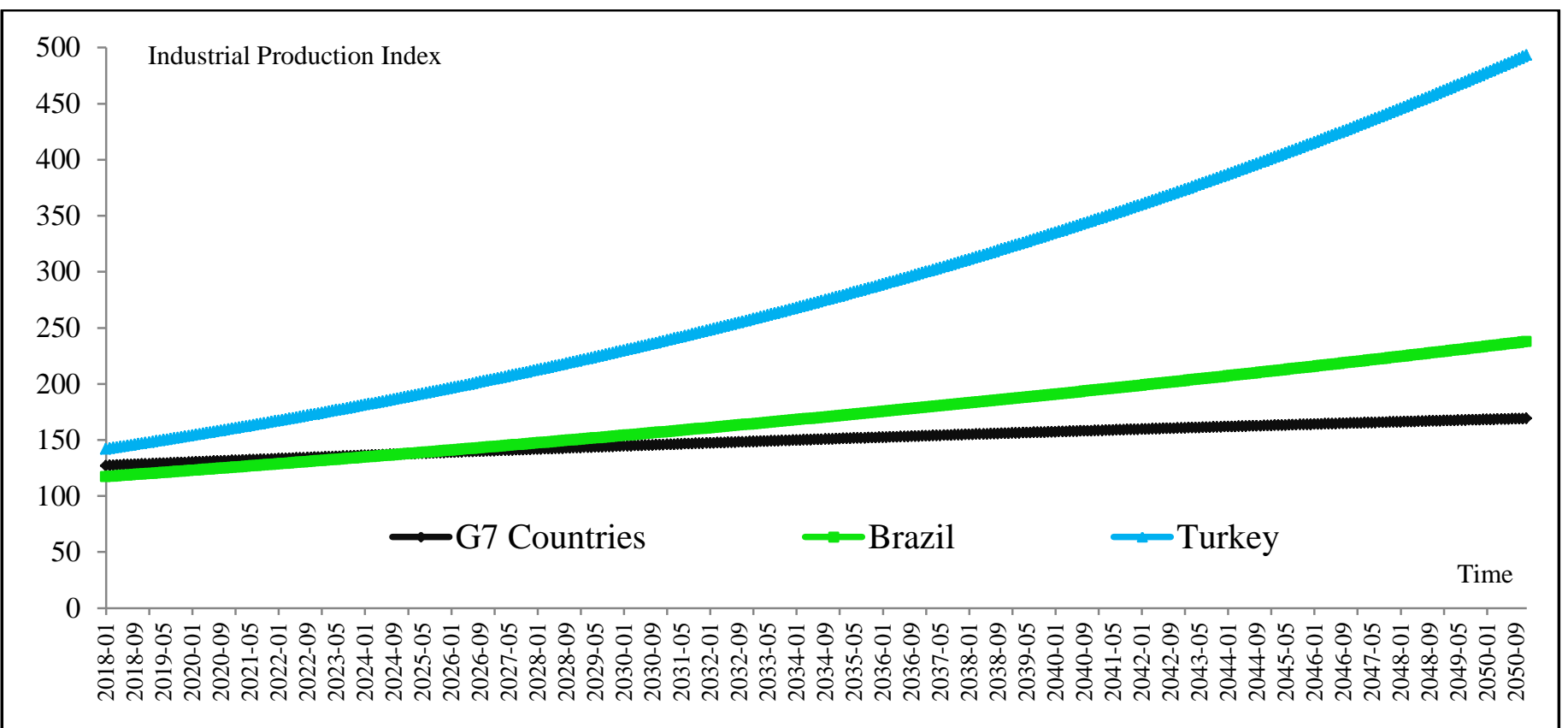

Figure 3. The forecasts of future changes in industrial production index values of Turkey, Brazil and G7countries in the period from 2018 to 2050 (based on 2010 data via Gompertz model)

\section{Conclusion}

As a result, it has been determined that modeling of industrial production index data with nonlinear regression models is sufficient for explaining data. According to the results of recent study, Turkey's industrial production increased to the least damage from the 2008-2009 crisis, and is increasing in a decisive way. In terms of predictions for the future, highly accelerated growth is expected in Turkey's industrial production index.

\section{References}

[1] R. C. Kormendi, P. G. Meguire, "Macroeconomic Determinants of Growth Cross-Country Evidence," Journal of Monetary Economics, 16, pp. 141-163, 1985.

[2] F. Schneider, "Size and Development of the Shadow Economy of 31 European and 5 Other OECD Countries from 2003 to 2014: Different Developments?," Journal of Self-Governance \& Management Economics, 3(4), pp. 7-29, 2015.

[3] N. O. Altay, M. Güçlü, M, "The Choice of Foreign Exchange Rate Regime: Fear of Pegging or Fear of Floating?," Yap1 Kredi Economic Review, XVI (2), pp. 85-98, 2005.

[4] E. Yalçın, E. Telatar, "Brezilya ve Türkiye Ekonomilerinin Benzerliği: Gerçek mi Yanilsama mi?" Expertise Proficiency Thesis. Publish of Central Bank of Turkey Republic, pp. 101, 2008. (in Turkish)
[5] K. Forbes, R. Rigobon, "No Contagion, Only Interdependence: Measuring Stock Market Comovements," The Journal of Finance, LVII, 5, pp. 2223-2261, 2002.

[6] J. C. Wu, F. D. Xia, "Measuring the Macroeconomic Impact of Monetary Policy at the Zero Lower Bound," Journal of Money, Credit and Banking, 48, pp. 253-291, 2016.

[7] K. J. Preacher, A. F. Hayes, "SPSS and SAS Procedures For Estimating Indirect Effects in Simple Mediation Models," Behavior Research Methods, Instruments, \& Computers 36 (4), pp. 717-731, 2004.

[8] M. Tabatabai, D. K. Williams, Z. Bursac, "Hyperbolastic Growth Models: Theory and Application," Theoretical Biology and Medical Modelling, 2, pp. 1-14, 2005.

[9] J. Y. Park, P. C. B. Phillips, "Nonlinear Regressions with Integrated Time Series", Econometrica, 69, pp. 117-161, 2008.

[10]SAS Institute, "SAS/STAT User's Guide," Version $6,5^{\text {th }}$ ed. SAS Inst. Inc., Cary, NC. 1999.

[11]T. Teräsvirta, H. M. Anderson, "Characterizing Nonlinearities in Business Cycles Using Smooth Transition Autoregressive Models," Journal of Applied Econometrics, 7, pp. 119136, 1992.

[12]H.A. Karaduman, "Asymmetric Behaviour of Growth Rate in Turkey: Lstar Model," 
Economics Business Finance, 23, pp. 115-132, 2008.

\section{Author Profile}

Dr. Nihan Öksüz Narinç received the M.S. and Ph.D. degrees in Economy from Social Sciences Institute of Akdeniz University, Antalya, Turkey, in
2012 and 2018, respectively. During 2015-2018, she worked as academic staff in Vocational School of Social Sciences of Namik Kemal University, Tekirdağ, Turkey. 